\title{
"PARA CADA PROBLEMA AFRICANO, EXISTE UMA SOLUÇÃO BRASILEIRA"? UMA ANÁLISE DOS MEGAPROJETOS BRASILEIROS EM MOÇAMBIQUE
}

\section{Daniela Pessoa de Goes Calmon ${ }^{1}$}

RESUMO: O artigo busca entender quais as condições existentes para que hoje estejam ocorrendo transformações em Moçambique que favorecem a exportação de produtos primários. Essas transformações são apresentadas pelos agentes proponentes como propostas de desenvolvimento e modernização e frequentemente são frutos de parcerias com governos dos chamados países emergentes (principalmente Brasil e China) ou da atuação de suas empresas. Dentre essas propostas, busca-se entender em particular as condições para a implementação de dois megaprojetos com forte participação brasileira: o programa de cooperação ProSavana entre Brasil, Moçambique e Japão e a construção da mina de carvão de Moatize pela Vale, empresa multinacional brasileira. Para esse propósito, são analisadas as condições macroeconômicas e o fenômeno de reprimarização e nova disputa por recursos naturais do continente africano, as condições favoráveis em Moçambique e o novo papel assumido pelo Brasil a nível internacional, para então abordar especificamente o ProSavana e a mina de Moatize.

Palavras-chave: Moçambique, cooperação Sul-Sul, reprimarização, agronegócio, mineração de carvão.

ABSTRACT The article aims to understand what the conditions are for the current transformations in Mozambique that favor the exportation of primary products. These transformations are presented by the propelling agents as development and modernization proposals and are frequently the product of partnerships with governments of countries referred to as "emergent" (mainly Brazil and China) or the operations of companies from these countries. Among these proposals, we aim to understand in particular the conditions for the implementation of two massive projects

${ }^{1}$ Estudante de graduação em Direito da Universidade Federal do Paraná (UFPR). Orientação nesse artigo pelo professor do Departamento de História da UFPR Hector Rolando Guerra Hernandez. 
with strong Brazilian participation: the cooperation program "Pro-Savana" between Brazil, Mozambique and Japan and the construction of the Moatize coal mine by Vale, a multinational Brazilian company. For this purpose, we analyze the macroeconomic conditions and the phenomenon of reprimarization and new scramble for African natural resources, the favorable conditions in Mozambique and the new role taken up by Brazil on an international level, before approaching Pro-Savana and the Moatize mine specifically.

Key words: Mozambique, South-south cooperation, reprimarization, agribusiness, coal mining.

\section{Introdução}

Nos últimos anos, diversas transformações têm sido pensadas e projetadas para Moçambique: algumas já estão sendo efetivamente implementadas; outras estão ainda em fase inicial de discussão. Essas mudanças ocupam um espectro amplo entre negócios privados e políticas de governo, envolvendo frequentemente uma mistura dos dois, mas têm em comum alguns elementos: crescentemente têm participação ou mesmo um papel central dos chamados países emergentes ${ }^{2}$, principalmente da China e do Brasil; têm pretensões de integrar Moçambique mais na economia mundial através de exportações de produtos primários e buscar a modernização do país; e refletem simultaneamente processos globais de novas tendências de acumulação

\footnotetext{
${ }^{2}$ Essa denominação, assim como a sigla BRICS, é recente e passível de diversos questionamentos. Para uma discussão sobre a inserção dos chamados países emergentes ou BRICS na ordem mundial, ver Capítulo 2 de GARCIA, 2012.
} 
do capital e uma conjuntura interna favorável a essas mudanças.

Escolhemos para esse artigo focar em dois megaprojetos que ligam Brasil e Moçambique:

1 - A construção e a operação de uma mina em Moatize pela empresa VALE, (construção iniciada em 2008, operante desde 2011), ou seja, uma atuação de uma empresa multinacional brasileira autorizada pelo governo moçambicano - que tem uma pequena participação nos lucros.

2 - O programa de cooperação ProSavana, destinado a reestruturar a agricultura do norte do país, em fase inicial de implementação e gerado a partir de um acordo de 2011 entre Moçambique, Brasil e Japão.

Esses projetos são visivelmente diferentes entre si, mas também acreditamos que:

a) inserem-se ambos dentro dos mesmos processos globais;

b) estão ambos ligados ao modo de utilização da terra e recursos, e à possível expropriação de quem ocupa os territórios atingidos no momento;

c) dependem de condições semelhantes para que possam estar ocorrendo agora. 
O objetivo principal desse artigo é justamente compreender quais são essas condições, isto é, quais são as condições, locais $e$ globais, para que essas transformações estejam ocorrendo agora, não pretendendo esgotá-las, mas focar principalmente no que diferencia o cenário atual de períodos anteriores. Iniciaremos, então, perquirindo sobre o contexto global e a inserção do continente africano na economia mundial, assim como sobre as tendências recentes mundiais em relação à agricultura, que são relevantes principalmente para compreender o ProSavana; e em seguida, investigaremos as condições internas moçambicanas e principalmente a disponibilidade do Estado moçambicano para tais empreendimentos. Na quarta seção, iremos abordar, sem querer aprofundar-nos excessivamente sobre a questão, o que possibilita que o Brasil, um país tradicionalmente considerado periférico (mas hoje cada vez mais qualificado como "emergente"), esteja ocupando um papel tão relevante nessas duas transformações e, por fim, analisaremos especificamente o mega-projeto de mineração de Moatize e o ProSavana à luz disso tudo, tangenciando possíveis consequências e a relação que esses empreendimentos denotam com o território e as territorialidades moçambicanos. 


\section{Contexto ampliado}

Segundo Patrick Bond (2008, p. 83), a crescente integração da África à economia mundial continua a gerar para o continente não riqueza, mas o escoamento de riqueza ${ }^{3}$. Historicamente, as economias africanas construíram-se enquanto economias dependentes periféricas (AMIN, 1972, p. 118). No período mercantilista - séculos XVII e XVIII -, de acordo com Samir Amin (1972, pp. 109-110), a África subsaariana cumpriu o papel de "periferia da periferia", isto é, supriu a demanda de trabalho escravo para as plantations das Américas (essa sendo a periferia que garantiu a acumulação monetária necessária naquele momento à burguesia no centro, na Europa ocidental). A real integração do continente ao sistema capitalista deu-se a partir do século XIX, em que:

The old periphery - America of the plantations - and its periphery - Africa of the slave trade - had to give way to a new periphery. The function of the new periphery was

\footnotetext{
${ }^{3}$ A mesma observação já tinha sido feita por Kwame Nkrumah em 1965, notando que as independências dos países africanos não tinham significado o fim das relações coloniais (agora sob forma de "neocolonialismo"): "A África é um paradoxo que ilustra e coloca em evidência o colonialismo. Sua terra é rica e no entanto os produtos que vêm do seu solo e do seu subsolo continuam a enriquecer, não predominantemente os africanos, mas grupos e indivíduos que trabalham para o empobrecimento da África." (NKRUMAH, 1967, p. 1)
} 
to provide products which would tend to reduce the value of constant capital and that of variable capital used at the centre: raw materials and agricultural produce. (AMIN, 1972, p. 113) ${ }^{4}$

É com a ocupação colonial (e o capital já em sua fase monopolista) que se torna possível explorar realmente os recursos naturais africanos e a força de trabalho barata. A partir daí, delineiam-se o que Amin (1972) chama de três “macrorregiões" do período colonial que cumprem predominantemente funções diferentes: a África da reserva de trabalho, no sul e leste do continente (destinando força de trabalho principalmente para a extração de minérios na África do Sul e Rodésia e para a agricultura de diferentes regiões), a África da economia colonial, correspondente à África ocidental tradicional (baseada na troca de commodities agrícolas fornecidas pela sociedade periférica pelos produtos de uma indústria capitalista central - a chamada économie de traite), e a África das companhias concessionárias, na bacia do Rio Congo. A divisão nessas macrorregiões continua válida como ferramenta para a compreensão

${ }^{4}$ Tradução livre: "A velha periferia - América das plantations - e a sua periferia África do tráfico escravo - tiveram que dar lugar a uma nova periferia. A função da nova periferia era fornecer produtos que tenderiam a reduzir o valor do capital constante e do capital variável usados no centro: matérias-primas e produtos agrícolas." 
atual da África, mas devemos atentar também para como novos processos históricos, dinâmicas, atores, e a descoberta e demanda de novas e diferentes matérias-primas (como minérios especificamente necessários aos aparelhos tecnológicos desenvolvidos nas últimas décadas) também favoreceram transformações no papel econômico cumprido pelos países africanos na economia global.

A tendência de espoliação da África não foi quebrada, porém, e hoje parece novamente intensificada - diversos autores falam em uma nova corrida pela África ou uma nova disputa por seus recursos ocorrendo a nível global. Minérios, petróleo, terra, produtos agrícolas, madeira: tudo é disputado, numa corrida na qual agora participam não só as tradicionais potências europeias e os Estados Unidos, mas também países emergentes, como Brasil, China, Índia e a própria África do Sul, que tem uma situação bastante particular dentro do continente africano. As razões para essa nova corrida são complexas e decifrá-las escapa ao escopo desse artigo - os debates sobre imperialismo, neocolonialismo, os papéis de centro e periferia, dependência e os mecanismos de acumulação do capital continuam vivos e controvertidos, com diversos autores sustentando inclusive a necessidade de novas teses sobre o imperialismo. Uma possibilidade de interpretação desse processo estaria no conceito de "acumulação por espoliação" de David Harvey. Segundo 
o autor (2004), não devemos compreender aquilo que normalmente chamamos dentro do marxismo de acumulação "primitiva" ou "originária" (aquela baseada geralmente na depredação, fraude ou violência) como apenas uma etapa inicial do capitalismo, que possibilitou sua consolidação, ou como algo exterior ao sistema capitalista, como postulou Rosa Luxemburgo, embora ela já tenha sido capaz de ver que a acumulação do capital era dual. A acumulação por espoliação é atual e liga-se a processos como:

mercantilização e privatização da terra e a expulsão forçada das populações camponesas; a conversão de diversas formas de direitos de propriedade -comum, coletiva, estatal, etc.- em direitos de propriedade exclusivos; a supressão do direito aos bens comuns; a transformação da força de trabalho em mercadoria e a supressão de formas de produção e consumo alternativos, incluindo os recursos naturais; a monetarização das trocas e a arrecadação de impostos, particularmente da terra; (...) o sistema de crédito (...). (HARVEY, 2004, p. 109)

Esses processos continuam "claramente presentes na geografia histórica do capitalismo" (HARVEY, 2004, p. 109). A acumulação pela reprodução ampliada do capital (pela exploração do trabalho vivo na produção) e a acumulação por espoliação coexistiriam, portanto, na análise de Harvey, mas haveria momentos históricos de predominância 
de uma ou de outra, e os sinais agora apontam para a reintensificação daquela: "O equilíbrio entre acumulação por espoliação e reprodução ampliada já se voltou a favor da primeira e é difícil imaginar que esta tendência faça outra coisa que se aprofundar, transformando-se no emblema daquilo que é o novo imperialismo..." (HARVEY, 2004, p. 119). Essa parece uma explicação plausível para atuais processos de espoliação e privatização de bens na África.

A África continua a cumprir, nesse cenário, o papel de periferia descrito por Amin, em que a exportação de matérias-primas e produtos primários é justamente um dos mecanismos principais que permitem uma troca desigual e o escoamento de riqueza apontado por Bond $(2007,2008)^{5}$. As políticas neoliberais implementadas nos anos 80 e 90 (que voltaremos a abordar adiante, especificamente em relação a Moçambique) favoreceram a "reprimarização" das economias africanas. Herrera, ao abordar os obstáculos ao pleno desenvolvimento da agricultura africana e razões para a atual crise dos alimentos, inclui:

\footnotetext{
${ }^{5}$ Existem diversos mecanismos de transferência de riqueza dos países periféricos para os países centrais. Outro digno de nota são os juros das dívidas externas dos países periféricos, as quais cresceram exponencialmente a partir dos anos 1970. "O caso latino-americano é emblemático: se, em 1975, a dívida externa de nossos países era estimada em 300 bilhões de dólares, em 2005 ela chegava a 730 bilhões - apesar de, nos mesmos trinta anos, nossos países terem pago um total de 1 trilhão de dólares." (NETTO; BRAZ, 2012, p. 246).
} 
la crises de la deuda externa em las naciones subdesarrolladas durante el decênio de 1980-1989 y la entronización de las políticas económicas neoliberales, que trajeron como consecuencia significativas obstáculos al desarrollo de su sector agrícola y su reorientación hacia los cultivos para la exportación, lo que provoco um proceso de reprimarización de estas naciones hasta de estrechamiento de sus estructuras econômicas. (HERRERA, 2011, p. 307) ${ }^{6}$

Moyo e Yeros (2008, p. 24) notam como a reação neoliberal a partir dos anos 70, ao contrário de discursos desenvolvimentistas anteriores que tendem a enfatizar a integração dos mercados nacionais nas suas próprias condições, exige a integração do nacional no global e mesmo coloca-a como solução para os problemas nacionais. Bond aponta no mesmo sentido e critica a armadilha da dependência de exportação de commodities em que as economias africanas caíram, incentivadas pelo neoliberalismo:

The most important myth of neoliberal economics is that production for export inexorably creates prosperity. In reality, 'unequal exchange' in trade - including the rising

\footnotetext{
${ }^{6}$ Tradução livre: “... a crise da dívida externa nas nações subdesenvolvidas durante o decênio de 1980-1989 e a entronização das políticas econômicas neoliberais, que trouxeram como consequência significativos obstáculos ao desenvolvimento de seu setor agrícola e sua reorientação para os cultivos de exportação, o que provocou um processo de reprimarização destas nações e até mesmo o estreitamento de suas estruturas econômicas."
} 
African trade deficit with South Africa - is another route for the extraction of superprofits from Africa. The continent's share of world trade declined over the past quarter century, but the volume of exports increased. (...) Overall, primary exports of natural resources accounted for nearly $80 \%$ of African exports in 2000, compared to $31 \%$ for all developing countries and $16 \%$ for the advanced capitalist economies. (BOND, 2008, pp. 88-89)

Entre esses recursos, sem dúvida o petróleo, o gás natural e os minérios que servem também como combustíveis fósseis ou alimentam as indústrias dos países centrais e emergentes ocupam um papel muito importante - Bond (2008, p. 89) assinala que $63 \%$ das exportações subsaarianas (excluindo a África do Sul) são relacionadas ao petróleo. Não é difícil relacionar a crescente importância da extração e exportação de carvão em Moçambique a essas tendências gerais africanas e a uma demanda tanto dos países do capitalismo avançado, profundamente industrializados, como dos países experimentando rápido crescimento econômico, como a China.

\footnotetext{
${ }^{7}$ Tradução livre: "O mais importante mito da economia neoliberal é que a produção para exportação inevitavelmente cria prosperidade. Em realidade, a "troca desigual" no comércio - incluindo o crescente déficit comercial africano com a África do Sul -é outra rota para extração de superlucros da África. A porção do continente no comércio mundial declinou no último quarto de século, mas o volume de exportações aumentou. (...) No todo, exportações primárias de recursos naturais foram responsáveis por quase $80 \%$ das exportações africanas em 2000, comparado a $31 \%$ para todos os países em desenvolvimento e $16 \%$ para as economias capitalistas avançadas."
} 
Por fim, devemos analisar as transformações da agricultura a nível mundial e especificamente na África nas últimas décadas para compreender o projeto de cooperação ProSavana à luz delas. A partir dos anos 60-70, o que se convencionou chamar de "Revolução Verde" (um processo de suposta modernização tecnológica, que prometeu - e não cumpriu - uma maior produtividade agrária e autossuficiência alimentar nacional, na verdade servindo para subordinar a periferia às empresas estadunidenses de sementes de alta tecnologia, produtos químicos e equipamentos agrícolas ${ }^{8}$ ) esteve associado a uma orientação da agricultura em um modelo capitalista monopolístico e agroexportador em diversos países, promovendo a modernização técnica e a expulsão em massa dos camponeses. ${ }^{9}$ Esse processo de expropriação massiva dos camponeses e a efetiva "modernização" do campo $^{10}$ ainda não ocorreu em larga escala na África: segundo Bernstein, en la mayor parte del África subsahariana, com excepción de los territórios de los estabelecimentos (blancos) más extensivos (Kenya,

\footnotetext{
${ }^{8}$ Ver MOYO; YEROS, 2008.

${ }^{9}$ Caso emblemático é o do próprio Brasil: "Entre 1985 e 1996, registraram-se no Brasil pelo menos a expulsão de 5,4 milhões de camponeses e a desaparição de 941.111 pequenas e médias explorações agrícolas." (ZIEGLER, 2013, p. 257)

${ }^{10}$ É digno de nota que apenas 3,8\% dos solos aráveis das África subsaariana estão irrigados e que aí existem apenas 85 mil tratores. $O$ instrumento principal da agricultura continua a ser a enxada de cabo curto e a grande maioria dos camponeses ainda praticam a "agricultura de chuva". (ZIEGLER, 2013, p. 83).
} 
el sur de Rhodesia, Sudáfrica), los granjeiros 'campesinos' (incluso los pastores) no fueron desposeídos, aunque sí "estimulados" por varios médios para entrar em la economia monetária (de mercancias) como produtores de bienes agrícolas y/o de fuerza de trabajo. (BERNSTEIN, 2008, p. 82) ${ }^{11}$

Abre-se a hipótese de que os projetos de cooperação técnica e o envolvimento de empresas estrangeiras na compra de terras e fomento à agricultura na África representem exatamente uma tentativa nesse sentido, de promover uma adequação maior da agricultura africana ao capitalismo global, ou ao menos de tornar a terra mais rentável aos interesses internacionais. Pesquisadores, ONGs e movimentos populares têm denunciado o crescente processo de açambarcamento de terras africanas nos últimos anos, os chamados "land grabs":

Na África, em 2010, 41 milhões de hectares de terras aráveis foram vendidos, arrendados ou apropriados sem contrapartida por hedge funds norte-americanos, bancos europeus e fundos dos Estados sauditas, sul-coreando, singapurense, chinês e outros. (ZIEGLER, 2013, p. 302)

11 Tradução livre: “... na maior parte da África subsaariana, com exceção dos territórios dos estabelecimentos (brancos) mais extensivos (Quênia, o sul da Rodésia, África do Sul), os agricultores "camponeses" (incluindo os pastores) não foram desapropriados, mas sim "estimulados" por diversos meios a entrar na economia monetária (de mercadorias) como produtores de bens agrícolas e/ou de força de trabalho". 
Dois outros fatores recentes têm tido ou ainda terão efeito sobre a questão agrária africana nos próximos anos: a nova demanda mundial por agrocombustíveis, isto é, pela transformação de produtos agrícolas em bioetanóis ou biodieseis, como substitutivos dos combustíveis fósseis, e, ainda, a crescente especulação sobre bens ligados à terra e à produção de alimentos. Quanto ao primeiro fator, é significativo que a produção mundial de agrocombustíveis tenha dobrado entre 2006 a 2011 (ZIEGLER, 2013, p. 244). Diversos projetos para a produção de agrocombustíveis já têm sido implementados na África ${ }^{12}$, inclusive em Moçambique. Ainda, não há como se ignorar o potencial impacto da crescente especulação sobre matérias-primas alimentares e sobre tudo que lhe é relacionado: insumos, sementes, adubos, os próprios alimentos e a terra. Segundo Ziegler (2013, p. 281), após a implosão dos mercados financeiros, grandes especuladores (em especial, os hedge funds estadunidenses) migraram para os mercados de matérias-primas, principalmente para os mercados agroalimentares. Esse é o outro fator

\footnotetext{
12 "Em Angola, o governo anuncia projetos que destinam 500.000 hectares de terras à cultura de agrocarburantes. (...) O governo do Benim propõe-se converter 300.000 a 400.000 hectares de zonas úmidas em plantações de palma oleaginosa no Sul do país. (...) Mas onde se anunciam alguns dos maiores projetos em matéria de agrocarburantes é na República Democrática do Congo. Em julho de 2009, a firma chinesa ZTE Agrobusiness Company Ltd. Divulgou seu projeto de implantar a cultura de palma oleaginosa, para produzir agrocarburantes, em um milhão de hectares. A ZTE já anunciara, em 2007, o investimento de um bilhão de dólares numa plantação de três milhões de hectares." (ZIEGLER, 2013, pp. 266-268)
} 
que favorece o açambarcamento de terras (já que a terra é um valor rentável e o preço dela nos países em desenvolvimento é em média 30 vezes menos elevado do que nos países do Norte) e a transformação da agricultura africana, favorecendo a implantação de novas monoculturas por trustes agroalimentares em solo africano. (ZIEGLER, 2013, p. 304).

\section{Condições favoráveis em Moçambique}

Moçambique é um país africano de colonização portuguesa cuja independência foi conquistada em 1975, após treze anos de luta. Embora os portugueses tenham chegado à costa moçambicana já no fim do século XV e ela tenha sido afetada severamente pela captura e tráfico de escravos nos séculos seguintes, assim como pelo estabelecimento de prazos portugueses ao longo do Rio Zambeze, é com a instalação das companhias concessionárias no fim do século XIX e, mais acentuadamente, com o regime de Salazar (1926-1970) que as políticas coloniais alcançam realmente o interior da região. Sob o regime de Salazar, são implementadas políticas de trabalho compulsório, incentivo e regulamentação do trabalho migratório para as minas da África do Sul e produção agrícola constrangida. Após a Segunda Guerra Mundial, Portugal intensificou seus empreendimentos 
coloniais em Moçambique, inclusive através de grandes projetos financiados pelo capital internacional, como a hidrelétrica de Cabora Bassa. Segundo Bernstein (2008, p. 82), Moçambique combinou elementos dos três tipos de economia colonial descritos por Amin (reserva de trabalho, a "économie de traite" e a pilhagem das companhias concessionárias), acima citados. Diferentemente de outros processos menos conflituosos de descolonização na África, Portugal opôs-se firmemente à independência de suas colônias e guerras armadas de libertação desenrolaram-se em Angola, Moçambique e GuinéBissau. Em Moçambique, a luta foi liderada pela FRELIMO - Frente de Libertação de Moçambique - para quem o poder foi transferido após a independência e que hoje ainda é o partido dominante no poder. A FRELIMO adotou oficialmente uma orientação marxista-leninista em 1977 e a partir daí empreendeu a nacionalização das terras e tentou dirigir a economia, além de investir pesadamente na saúde e na educação. (MIDDLETON; MILLER, 2007, p. 610) Na área da agricultura, seu foco era desenvolvê-la e modernizá-la através de grandes fazendas estatais ${ }^{13}$ e tentou-se concentrar os camponeses em

\footnotetext{
13 Essas seguiam o modelo de plantations e seria o espaço privilegiado de modernização e uso de novas tecnologias. Foram criadas mais de 100 fazendas estatais, com mais de 600.000 hectares de terras produtivas. (OAKLAND INSTITUTE, 2011, p. 10).
} 
aldeias comunais e cooperativas ${ }^{14}$. Essas medidas estavam ligadas a uma

visão específica sobre a criação de uma nova nação após a obtenção da independência, que ocorreria em 1975. Tratava-se de uma visão grandiosa de modernização construída com base nas raízes e preconceitos do grupo [a classe assimilada sobretudo urbana ou não agrícola que formava a dirigência da FRELIMO], que tendia a ver os camponeses, a grande maioria da nação, como tabula rasa, ou seja, algo que podia ser completamente remodelado de acordo com o seus planos para o futuro. $(\mathrm{SUMICH}, 2008$, p. 326)

As tentativas de construção da nova nação logo sofreram o forte abalo de uma guerra civil de desestabilização, provocada pela RENAMO - Resistência Nacional Moçambicana - que foi apoiada primeiramente pelo regime branco da Rodésia do Sul e depois pela África do Sul. A guerra civil durou de 1977 a 1992 e resultou na morte

\footnotetext{
14 "Empreenderam-se esforços no sentido de transferir os camponeses dos seus pequenos agregados residenciais dispersos para aldeias comunais centralizadas, que se tornaram 'cidades no mato'." (SUMICH, 2008, p. 330).

${ }^{15}$ Segundo Sumich, a ideologia da modernidade da FRELIMO foi reformulada após o colapso de sua versão nacionalista revolucionária, mas continua viva hoje como forma de legitimar as elites (afirmando sua igualdade com o mundo exterior ao mesmo tempo em que justifica a hierarquia e desigualdade interior no país ) e numa reafirmação da promessa do progresso, para cuja realização as elites seriam indispensáveis, "as únicas detentoras das competências e capacidades necessárias ao cumprimento dessa promessa", segundo o discurso. Ibidem, pp. 321-322.
} 
de um milhão de pessoas, no desalojamento de cinco milhões, na destruição da infraestrutura e fortes prejuízos econômicos. (MIDDLETON; MILLER, 2007, p. 610)

Nos anos de 1983 e 1984, frente à crise na economia, a FRELIMO decide mudar sua estratégia econômica e afasta-se progressivamente de sua postura marxista. Em 1984, postula sua candidatura ao FMI e dois anos depois, dá início ao "programa de ajuste estrutural" comandado pelo Banco Mundial e pelo FMI, que vai principalmente promover a transferência de recursos e iniciativas do setor público para o privado sob o mantra do discurso neoliberal então hegemônico. É a FRELIMO, portanto, que vai realizar a privatização de diversos setores da economia e a transição para um capitalismo de mercado liberal. (VISENTINI, 2012, pp. 116-117).

Pitcher (2002, p. 101), baseando-se na análise de Róna-Tas sobre a transição de economias socialistas para o capitalismo, divide esse processo em dois períodos: o primeiro, de 1983 a 1990, representou a erosão do setor estatal, e foi um momento em que indivíduos buscaram ganhos próprios em meio a essa desestruturação; no segundo, de 1990 em diante, existe efetivamente a transição para a propriedade privada e a economia de mercado, e é o Estado que gerencia essa transição, tomando inclusive medidas legislativas e 
estabelecendo as condições necessárias para a criação dessa economia. Até 2002, o governo moçambicano tinha vendido cerca de 1000 pequenas, médias e grandes empresas estatais em todos os setores da economia, incluindo indústria, agricultura, construção, energia, transporte e água. (PITCHER, 2002, pp. 126-127) Essa privatização esteve ligada tanto a uma reabertura para entrada de capital estrangeiro quanto ao favorecimento de elites (novas ou velhas) nacionais, principalmente de membros da FRELIMO: "as elites políticas não só usaram o seu acesso ao poder para beneficiarem das privatizações, como também construíram uma base de apoiantes entre as elites do sector privado que lhes permitiu manterem o poder político." (PITCHER, 2003, p. 808). Quanto ao investimento estrangeiro possibilitado pela privatização, esse se concentrou nas empresas maiores vendidas pelo Estado e em novos projetos de megainvestimento. Pitcher comenta:

As of 1997, foreign investment accounted for about 50 percent of the total equity of the medium to large companies sold by the state, even though foreign investors only purchased 25 companies out of the 115 that were sold. (...) In addition, foreigners have proposed new investments in huge, mega-projects in industry, tourism, 
and mineral resources as well as in proposed transport corridors (...) (PITCHER, 2002, p. 147) ${ }^{16}$

Argumentamos que o investimento estrangeiro e a dependência da exportação de produtos primários continuam a gerar predominantemente a saída de riqueza do país ${ }^{17}$, porém, há também elites que se beneficiam nacionalmente e que favorecem esse tipo de investimento, afinal, quase todo o investimento estrangeiro é feito na forma de joint-ventures com participação do Estado ou de investidores nacionais. (PITCHER, 2002, p. 150). Assim, as empresas internacionais buscam alianças domésticas e o capital nacional ${ }^{18}$ tem tido um papel

${ }^{16}$ Tradução livre: "Em 1997, investimento estrangeiro era responsável por 50 por cento do capital total das empresas médias a grandes vendidas pelo Estado, ainda que investidores financeiros só tivessem comprado 25 empresas das 115 que foram vendidas. (...) Além disso, estrangeiros têm proposto novos investimentos em imensos mega-projetos em indústria, turismo, e recursos minerais, assim como propostas de corredores de transporte (...)".

${ }^{17}$ Por exemplo, no mega-projeto de Mozal, o governo fica com apenas 4 milhões dos cerca de 65 milhões de dólares gerados de lucro por ano, e o resto é repatriado. (BELLUCI, 2008, p. 126)

${ }^{18}$ Pitcher identifica quatro grupos de capital doméstico em Moçambique, sendo que quase todos têm algum tipo de conexão com o Estado: a) as companhias poderosas como JFS, Grupo Madal e Grupo Entreposto, que eram companhias concessionárias coloniais que permaneceram depois da independência; b) empresas que frequentemente estão em Moçambique desde o século XIX ou começo do XX, com investidores cujas origens podem ser traçadas para Portugal, Índia, Paquistão, China e até Grécia; c) novos capitalistas que transitaram da política aos negócios, isto é, são membros que vieram do governo e da política e conseguiram vantagens econômicas pelo clientelismo ou patronato; d) por fim, milhares de indianos e africanos de menor 
importante nesses processos. O próprio governo, na onda das privatizações, reconheceu não só a importância do capital estrangeiro (sua participação é frequentemente buscada de maneira ativa pelos oficiais de governo e instituições, pelo oferecimento de incentivos ao investimento, benefícios fiscais e opções atrativas para a repatriação de lucros), como também do fomento ao capital nacional (PITCHER, 2002, pp. 135-136). Como mencionado acima, uma das tendências de participação de empresas e de capital estrangeiro é em mega-projetos, dos quais o mais significativo foi à construção do complexo de fundição de alumínio de Mozal (projeto aprovado pelo governo valendo 1.34 bilhão de dólares), terminado em 2000, com investimento sul-africano, inglês e japonês, e que em 2004 já fornecia dois terços das receitas de exportação (MIDDLETON; MILLER, 2007, p. 610). Outros megaprojetos que vêm sendo discutidos são a duplicação da capacidade de Mozal, a expansão da hidrelétrica de Cabora Bassa, novo projeto hidrelétrico de Mepanga e dois projetos de gás (BELLUCI, 2008, p. 128) - os megaprojetos de mineração na região do Tete com certeza entram nesse leque. Segundo Belluci (2008, pp. 128-129), esses megaprojetos terão um grande impacto no PIB e na balança comercial de Moçambique, mas não na renda nacional e na balança de

capital, donos de lojas, acionistas em indústrias, grandes fazendeiros, etc. (PITCHER, 2002, pp. 154-167) 
pagamentos, por causa de repatriação de lucros e dos fluxos financeiros de retorno para pagamento de dívidas - acabam assim sendo uma nova forma de espoliar o povo moçambicano.

Quanto à agricultura, não houve em geral políticas vantajosas para os pequenos agricultores nas últimas décadas. As políticas agrícolas a partir dos anos 80 contribuíram no aumento das desigualdades econômicas e regionais, na medida em que priorizaram grandes empresas e acentuaram a insegurança da posse dos camponeses. (PITCHER, 2002, p. 113)

Nos anos 90, o aprofundamento das políticas de privatização e as tendências internacionais favoreceram o crescimento de grandes companhias privadas. Apesar da onda de privatizações e políticas neoliberais, a terra continuou a ser propriedade do Estado em Moçambique, que pode conceder o seu uso a companhias e indivíduos. A Lei de Terras de 1997 representou um avanço no reconhecimento dos direitos dos camponeses (respeitam-se direitos tradicionais de ocupação e investidores privados devem em tese consultar comunidades locais quando se candidatam para terra e concessões de madeira), mas tendências recentes de concessão de terras pelo governo moçambicano a 
estrangeiros são fonte de preocupação ${ }^{19}$. Há quem afirme que esse processo tem sido freado. Como indício, apontam que o Plano Estratégico de Desenvolvimento do Sector Agrário, lançado em 2011, indica a priorização do investimento doméstico e dos pequenos e médios agricultores. Porém, as ações e discursos têm sido contraditórios ${ }^{20}$, motivando o questionamento por parte das uniões camponesas: iriam projetos como o ProSavana realmente beneficiá-los? Atualmente, cerca de $80 \%$ da população moçambicana (estimada em 21 milhões) dedicase à agricultura, mas pelo menos $35 \%$ dos lares do país enfrentam insegurança alimentar crônica (CLEMENTS; FERNANDES, 2012, pp. 10, 13). Nos anos 80 e 90, a agricultura moçambicana foi fortemente prejudicada por uma série de secas e enchentes, além, evidentemente, da guerra civil - em algumas regiões, a produção de alimentos caiu $80 \%$ e, em 1992, o déficit de alimentos chegou a 1,3 milhões de toneladas. A produção agrícola tem crescido novamente, mas Moçambique ainda importa mais alimentos do que exporta, com um déficit no comércio de alimentos de US\$ 218 milhões em 2004. (GALL; HOBBY, 2007, pp.

${ }^{19}$ Entre 2004 e 2010, Moçambique concedeu quase 1 milhão de hectares $(2,5 \%$ da terra arável do país!) a empresas estrangeiras, $73 \%$ para florestamento e madeira e 13\% para agrocombustíveis e açúcar. (OAKLAND INSTITUTE, 2011, p. 5)

${ }^{20}$ Um mês antes do lançamento desse Plano, o ministro moçambicano de agricultura José Pacheco estava no Brasil num seminário de investimentos em que convidou fazendeiros brasileiros experientes para virem a Moçambique replicar o suposto 'boom' agrícola que tinham criado no Brasil. (OAKLAND INSTITUTE, 2011, p. 45) 
492-493). Não devemos render-nos aos discursos que atribuem as crises de alimentos na África somente a fenômenos naturais (como secas) ou à falta de tecnologia. A insegurança alimentar experimentada em diversos países da África também está vinculada ao impacto das políticas agrícolas das nações desenvolvidas (com fortes subsídios de seus governos), assim como às políticas neoliberais implementadas nos próprios países africanos, trazendo obstáculos ao desenvolvimento do setor agrícola e favorecendo a reorientação para cultivos de exportação (conforme já citado - HERRERA, 2011, p. 307), além da falta de acesso a crédito, aos mercados e de capital para compra de insumos por parte de camponeses.

\section{O papel do Brasil}

Nos últimos anos, o Brasil tem assumido uma maior proeminência internacional, tanto enquanto ator político e diplomático como economicamente, pela internacionalização de empresas brasileiras. Segundo o Boston Consulting Group (2013), o país está em terceiro lugar na lista dos países emergentes (atrás da China e da Índia) com treze empresas capazes de desafiar globalmente (são as "global challengers") as maiores companhias internacionais. Essas são: 
Camargo Corrêa, Embraer, Gerdau, Ioschpe-Maxion, JBS-Friboi, Marcopolo, Natura, Odebrecht, Brazil Foods, Petrobras, Tigre, Votorantim e WEG, e já a Vale é a única empresa brasileira já considerada consolidada a nível internacional, e não apenas uma desafiadora. Garcia (2012, p. 62) afirma que, a partir de 2003 (isto é, com o início do governo Lula), teria iniciado uma nova fase de expansão do capital com sede no Brasil, favorecida por políticas públicas e de crédito, que tem se traduzido nas novas posturas e papéis assumidos pelo país enquanto economia "emergente", que busca mais espaço no cenário internacional. Os números refletem essa realidade: em 2007, as 20 maiores multinacionais brasileiras investiram juntas 56 bilhões de dólares no exterior. Setores de destaque têm sido o petróleo, construção e engenharia, metais e mineração, e alimentos. A atuação dessas empresas a nível global e a sua associação com o Estado brasileiro tem gerado um debate sobre se o Brasil poderia estar assumindo um papel ou posição imperialista ou subimperialista no cenário global, em relação a outros países do Sul. ${ }^{21}$

\footnotetext{
${ }^{21}$ Ver o debate no Dossiê: Imperialismo brasileiro? da Revista Crítica Marxista ${ }^{\circ} 36$ (2013). São dignas de nota a posição de Virgínia Fontes (detalhada em FONTES, 2010), para quem o Brasil teria passada a integrar o grupo dos países capitalimperialistas, ainda que numa inserção secundária, e a de Mathias Luce, que resgata o conceito de subimperialismo de Ruy Mauro Marini para explicar a posição brasileira.
} 
A internacionalização dessas empresas está ligada de fato a políticas do Estado brasileiro, em especial à política de crédito operacionalizada pelos empréstimos do BNDES (Banco Nacional de Desenvolvimento Econômico e Social), que hoje supera o Banco Mundial em volume de empréstimos (em 2010, o BNDES concedeu 96 bilhões em empréstimos, 3,3x mais do que o Banco Mundial) e promoveu, a partir de 2003, uma linha de crédito específica para internacionalização das empresas brasileiras (GARCIA, 2012, p. 112). A política de governo a nível internacional tem se apoiado no tripé investimento, financiamento e cooperação internacional, e no governo Lula, houve uma reorientação da política externa pros países do Sul:

Com o governo Lula, o país procurou fortalecer as relações com outros países "do Sul", aprofundando e expandindo políticas de integração regional sulamericana, aproximando-se política e economicamente da China, Índia e Rússia, expandindo as relações com países da África e do Oriente Médio. Essa maior ênfase nas relações 'Sul-Sul' é acompanhada pela crescente expansão internacional de grandes grupos econômicos com sede no Brasil para esses países e regiões. (GARCIA, 2012, p. 16) (grifos nossos)

Nessa conjuntura, a África ganhou uma importância sem precedentes na política externa brasileira, e tem sido também tanto 
objeto de investimentos, financiamentos como projetos de cooperação técnica, em especial nas áreas de agricultura e saúde. Esse crescente interesse nos países africanos pelo Brasil tem sido justificado pelos fins de cooperação Sul-Sul ${ }^{22}$ e por laços linguísticos e históricos que o unem principalmente aos países de colonização portuguesa e aos locais de onde foram tirados os escravos para envio ao Brasil. Diversas empresas (com destaque para a construção civil) já estão instaladas em países africanos (o caso mais notório é o da Odebrecht em Angola) e, ainda,

segundo a Fundação Dom Cabral, a África desponta hoje como continente alvo para os investimentos brasileiros, com a entrada da Votorantim em cinco países africanos (...); a entrada da Randon na Argélia e Quênia; a Weg iniciou operações no Sudão e na República de Senegal. A Marfrig e Totvs aumentaram sua presença no continente, além da Petrobras e da construtora Odebrecht (...). (GARCIA, 2012, p. 69).

A concessão de créditos do BNDES para projetos na África foi de US\$ 766 milhões em 2009, representando 36\% dos desembolsos do Banco em financiamento internacional. (GARCIA; KATO; FONTES,

${ }^{22}$ Conforme reiterado por Dilma em sua visita a Adis Adeba em abril desse ano, para os 50 anos da União Africana: "O Brasil quer, não só estabelecer relações comerciais, investir aqui, vender para o país, mas também uma cooperação no padrão Sul-Sul.” (LOURENÇO, 2013) 
2013, p. 12).

A VALE é uma das empresas cuja inserção na África tem aumentado. Como já mencionado, a VALE já é uma multinacional consolidada a nível global ${ }^{23}$ : é a segunda maior empresa de mineração do mundo, e tem presença nas bolsas de São Paulo, Nova York, Madrid e Hong Kong. Segundo Garcia (2012, p. 97):

a África tornou-se um novo território de expansão para a mineradora entre 2003 e 2007, quando adquiriu subsidiárias no Gabão, Moçambique, Angola e África do Sul. A entrada em Moçambique, em 2004, deu início a uma terceira fase de internacionalização. A mina em Moatize é considerada um marco na estratégia de exploração de carvão e uma possível plataforma de expansão para outros países africanos. Para Agnelli [presidente da Vale de 2001 a 2011], estar na África é um vantagem comparativa enorme devido às fontes de recursos naturais ainda intactas. (...) Atividades na África, apesar de apresentadas como um 'mercado natural' para o Brasil (devido a similitudes de língua e história), visam a garantir espaços de exploração na competição com as empresas chinesas, com vistas ao mercado daquele país.

${ }^{23}$ Interessante que a própria expansão da VALE, já nos anos 60 e 70, esteve sempre ligada ao mercado estrangeiro e capital externo: "A descoberta pela U.S. Steel, em 1940, da maior reserva do mundo de minério de ferro no Carajás, forçou a intervenção do governo para que esta entrasse em associação com a VALE que, por sua vez, assumiu o projeto por completo em 1977. Também nesse período, ela se associou à canadense Alcan para produção de bauxita. Entre 1969-79, suas vendas ao exterior cresceram $285 \%$, tornando-se a maior exportadora de minério de ferro do mundo até hoje." (GARCIA, 2012, p. 94) 
Outro eixo de atuação brasileira na África é a cooperação técnica e a chamada ajuda para o desenvolvimento. Foi durante os mandatos do governo Lula, que se estenderam de 2003 a 2010, que o Brasil passou de receptor para doador de ajuda internacional e que a cooperação prestada a outros países em desenvolvimento saltou de cerca de US\$ 1,5 milhão em 2003 para mais de US\$ 33 milhões em 2010, levando em conta somente projetos e atividades isoladas da Agência Brasileira de Cooperação (ABC). A África recebeu cerca de $50 \%$ dessa ajuda e Moçambique é o principal país receptor de cooperação (15,78\%), seguido de Timor Leste e Guiné-Bissau. (GARCIA, 2012, p. 149). Enquanto a atuação de empresas como a VALE e a Odebrecht tem mais claramente uma direção visando vantagens para o Brasil (ou melhor, para suas classes dominantes) e seus impactos sociais e ambientais negativos já têm sido denunciados mais consistentemente, as atuações empreendidas diretamente pelo governo (e entidades estatais, dentre as quais a Embrapa e a Fiocruz têm destaque), pelos projetos de cooperação técnica e auxílio ao desenvolvimento, escondem os possíveis interesses sob discursos de solidariedade e mesmo fraternidade entre o Brasil e África, ou colocam-se como situações de benefício para todos os partícipes ("winwin"). Porém, é preciso entender que, a cooperação não está cindida 
totalmente de interesses comerciais ${ }^{24}$, e também pode servir como forma de ajuste dos países africanos a demandas da economia global, pela "exportação" ou implementação de certos modelos de desenvolvimento. Exemplo emblemático dessa mistura de interesses é a política brasileira de incentivo internacional à produção e uso de agrocombustíveis, focada no etanol, que se encaixa nas tendências analisadas na seção anterior desse artigo. ${ }^{25}$ De fato, a agricultura é uma das principais áreas de cooperação do Brasil na África e

abrange, segundo White, 'todas as facetas' da aspiração global do Brasil e seus objetivos de política externa, uma vez que alimentos e segurança energética são prioridades na agenda multilateral (...). O deslocamento da produção mundial de alimentos e agrocombustíveis para a África e outros países em desenvolvimento se encaixaria na

${ }^{24}$ Um forte indicativo de que o Brasil na verdade quer cada vez associar mais essas políticas está nas declarações recentes da presidente Dilma, sobre o interesse em criar uma nova agência de comércio e desenvolvimento, semelhante às dos países desenvolvidos, que poderia inclusive condicionar o auxílio técnico e financeiro à criação de vantagens comerciais para o Brasil: "Vamos criar uma agência de comércio como todos os grandes países têm. Será uma agência de cooperação, mas também uma agência comercial, com escopo grande." (PARAGUASSU, 2013)

25 “... uma das principais iniciativas é a ação de Cooperação Internacional para a Difusão da Agroenergia, baseada na estruturação de programas de fomento à produção e ao uso de etanol e biodiesel em terceiros países. (...) A Embrapa é um dos principais atores nessa área. Ela vem passando por um processo de internacionalização amplo, com escritórios e laboratórios em todos os cinco continentes. Na África, seu escritório é em Gana, onde possui um dos principais projetos de agrocombustíveis. (...)" (GARCIA, 2012, p. 152) 
estratégia brasileira mais ampla de elevar a cooperação e a integração do mercado Sul-Sul. Desse modo, para o autor, a cooperação em agricultura e etanol torna-se 'uma nova fronteira do engajamento entre o Brasil e o continente africano.' (GARCIA, 2012, p. 153)

Ainda, é interessante avaliar se as políticas de cooperação brasileiras - e aí o ProSavana estaria incluso - não visam reproduzir na África um certo modelo de desenvolvimento que vem se consolidando no Brasil, que continua a pautar largamente sua economia na exportação de commodities: como afirma Pierri, receitas de commodities continuam a ser a única fonte relevante de superávit na balança de pagamentos do país (PIERRI, 2013, p. 70) ${ }^{26}$. Emblemática seria então a frase citada por Celso Amorim, ex-ministro das relações exteriores brasileiro: "Para cada problema africano existe uma solução brasileira"27. Os responsáveis pela internacionalização das empresas e por essas políticas de cooperação parecem em geral partir do

\footnotetext{
${ }^{26}$ Interessante, nesse sentido, a análise de Delgado sobre o papel da agroexportação no Brasil: "A política de comércio exterior é alterada ao longo do segundo governo [de Cardoso] e passa a perseguir a estratégia abandonada em 1994: gerar saldos de comércio exterior a qualquer custo para suprir o déficit da conta-corrente. (...) Outra vez, como ocorrera na primeira crise da dívida em 1992, os setores primárioexportadores são escalados para gerar esse saldo comercial. Nesse contexto, a agricultura capitalista, autodenominada de agronegócio, volta às prioridades da agenda da política macroeconômica externa e da política agrícola interna. (...)" (DELGADO, 2010, pp. 93-94)

27 Celso Amorim está citando um professor queniano, chamado Calestou Juna. (AMORIM, 2011)
} 
pressuposto que o agronegócio, a intensa extração mineral e a dependência em exportação de commodities primárias são soluções, e não problemas. Não duvidamos que sejam soluções para alguém - a pergunta a ser feita é se são realmente soluções para as populações que os promotores dos projetos alegam beneficiar e se, justamente, essas populações não deveriam participar da construção de soluções para os problemas que enfrentam.

\section{O ProSavana e a mina de Moatize}

Com as análises acima, podemos entender que a implantação do ProSavana e a construção da mina de Moatize pela VALE não são eventos isolados: inserem-se dentro de dinâmicas e processos históricos, econômicos, políticos e sociais mais amplos, e são possíveis hoje por causa das condições acima descritas: uma economia mundial para a qual interessa que a África continue a exportar produtos primários, um papel mais proeminente brasileiro a nível internacional e interesse diplomático-comercial do país em estreitar suas relações com os países africanos, abertura do governo moçambicano para a entrada de capital estrangeiro, para a cooperação e para a chamada modernização agrícola, além de interesses do capital nacional. 
Como abordado acima, a mina de Moatize insere-se numa tendência de fomento (por investimento direto estrangeiro) a megaprojetos de capital intensivo em segmentos como extração mineral e energia. Com a descoberta de carvão metalúrgico de alta qualidade (a província de Tete tendo uma das maiores reservas de carvão do mundo ainda a serem exploradas, estimada em 23 bilhões de toneladas) e a crescente demanda de China, Índia e Japão, tem havido uma onda de interesse de investidores nas atividades de mineração a despeito das dificuldades moçambicanas de infraestrutura ${ }^{28}$. Segundo a Human Rights Watch (2013), a liberação de concessões para a mineração na região de Tete e a importância do carvão para a economia moçambicana têm crescido vertiginosamente nos últimos anos: o governo aprovou até outubro de 2012 ao menos 245 concessões de mineração e licenças para exploração na província de Tete, equivalentes a 3,4 milhões de hectares ou $34 \%$ da área da província. Se incluímos os pedidos aguardando aprovação na conta, a quantidade de terra atingida passa para assombrosos 6 milhões de hectares. Além da VALE, três outras grandes empresas estrangeiras já iniciaram suas operações de mineração em Tete: a Rio Tinto (anglo-australiana), a Jindal Steel and Power Limited (indiana) e a Beacon Hill Resources (inglesa). Em 2012, carvão já tinha

\footnotetext{
${ }^{28}$ Há evidências de que as prospecções da mina de Moatize já teriam sido feitas pela República Democrática Alemã nos anos 80.
} 
passado a ser a segunda maior exportação moçambicana, atrás apenas do alumínio. Em 2004, a Vale obteve permissão do governo moçambicano para explorar carvão e em 2007, obteve uma concessão de mineração de 35 anos no distrito de Moatize, província de Tete - a construção da chamada mina de Moatize iniciou em 2008 e a mineração iniciou efetivamente em maio de 2011.

A VALE espera exportar até 11 milhões de toneladas de carvão por ano na primeira fase e aumentar essa meta para 22 milhões de toneladas na segunda fase, com novas possibilidades de expansão ligadas à capacidade de melhoramento da infraestrutura de transporte. ${ }^{29}$ Nos termos da concessão, o governo moçambicano pode reservar até $25 \%$ das cotas do empreendimento e em 2012, o governo adquiriu 5\% das cotas e reservou 10\% para investidores particulares de Moçambique, confirmando o que apontamos na terceira seção sobre as alianças entre governo, capital nacional e capital internacional. A VALE ainda beneficia-se de imensos incentivos fiscais em sua operação. (MOSCA; SELEMANE, 2011, p. 20) A atuação de

\footnotetext{
${ }^{29}$ Recentemente, a Vale anunciou que, além do ferro de Carajás (PA), o outro grande projeto a que vai dar prioridade nos próximos anos é o negócio de carvão de Moatize, e que para isso prevê a duplicação do projeto com investimentos de US\$ 2 bilhões (previsão de entrada em operação no segundo semestre de 2015) e o investimento na modernização e construção de ferrovia ao longo do corredor Nacala (previsão de investimentos de US\$ 4,4 bilhões e entrada em operação em 2014). (GOÉS; RIBEIRO, 2013)
} 
mineradoras como a Vale tem sido alvo de críticas, em especial por forçarem a remoção de famílias habitantes no local. A construção da mina de Moatize promoveu a remoção de 1365 famílias, que foram reassentadas em um bairro urbano, em um assentamento rural ou receberam assistência para comprar uma nova casa ou compensação financeira. Denúncias têm sido feitas relatando que muitas famílias tiveram suas terras agrícolas reduzidas, substituídas por terras de menor qualidade ou que a alocação de terras prometida ainda não foi realizada, prejudicando a segurança alimentar e o direito à alimentação, além de haver denúncias de fornecimento errático de água, entre outros problemas. (HUMAN RIGHTS WATCH, 2013).

O ProSavana (Programa de Cooperação Triangular para o Desenvolvimento Agrícola das Savanas Tropicais de Moçambique) é um programa de cooperação em fase inicial que também tem gerado preocupações aos movimentos camponeses quanto à possibilidade de sua expulsão da terra ou de prejuízo à segurança alimentar, na medida em que promove cultivo de commodities de exportação e não de alimentos de subsistência. As primeiras notícias em relação a ele, em 2011, anunciavam que o governo de Moçambique estaria cedendo o uso (concessão de 50 anos) de 6 milhões de hectares no norte do país para 
fazendeiros brasileiros plantarem soja, algodão e milho ${ }^{30}$. Depois, esses boatos foram apaziguados e o governo anunciou que não estaria cedendo terras, mas que o ProSavana é um programa de cooperação técnica que vai qualificar e integrar o trabalho dos próprios camponeses (CLEMENTS, FERNANDES, 2012, pp. 17-18). O que se sabe do ProSavana oficialmente (embora uma das grandes críticas é justamente que ele vem sendo desenvolvido e implementado às escuras, sem discussão com a sociedade civil e os camponeses) é que é um programa de cooperação a partir de um acordo e parceria triangular entre Brasil, Japão e Moçambique ${ }^{31}$ que planeja atingir 14 milhões de hectares ao longo do Corredor de Nacala, que perpassa as três províncias mais ao norte de Moçambique (Niassa, Nampula e Zambézia), desenvolvendo e modernizando a agricultura. Segundo a Embrapa, a entidade a frente do projeto pelo lado do Brasil, o ProSavana estrutura-se em três componentes e objetivos:

a) melhorar a capacidade de pesquisa e extensão para o desenvolvimento de agricultura do Corredor de Nacala;

\footnotetext{
${ }^{30}$ Ver, por exemplo, RAFAEL, 2013.

${ }^{31}$ Curiosamente, apesar do Brasil alegar que seus projetos de cooperação sempre são orientados pela demanda dos países beneficiários, a ideia do ProSavana apareceu num fórum internacional em 2009, numa discussão somente entre Brasil e Japão. Depois se identificou Moçambique como o "beneficiário" mais apropriado e o acordo trilateral foi assinado em setembro de 2009. (CHICHAVA et al, 2013, p. 11)
} 
b) implementar projetos-piloto produtivos para pequenos agricultores e agricultores comerciais; e

c) formular um Plano Diretor de integração agro-industrial para o Corredor, com um foco maior de desenvolvimento regional (CHICHAVA et al, 2013, p. 12).

Esses componentes seriam viabilizados por projetos individuais ${ }^{32}$.

A implementação teve início em 2011 e prevê um cronograma de vinte anos. Sabemos ainda que o ProSavana se inspira no Prodecer, programa de cooperação entre Brasil e Japão iniciados nos anos 70, que foi um dos responsáveis pela transformação do Cerrado brasileiro num pólo de exportação de commodities, em especial, da soja e que, ao contrário do prometido, não promoveu a segurança alimentar, mas sim a concentração de terras e a degradação ambiental. (CLEMENTS, FERNANDES, 2012, pp. 2-3, 22). Ao que tudo indica, o ProSavana visa replicar o modelo do capitalismo agrário brasileiro ${ }^{33}$, e faz sentido

32 O ProSavana - Projeto de Investigação (iniciado em 2011 e previsto para durar 5
anos - através dele, já foram separados culturas para teste, dentre as quais se
encontram, além de cultivos tradicionais camponeses (arroz, cassava, feijão), também
soja, algodão e milho, tradicionais commodities) o ProSavana - Plano Diretor, e o
ProSavana Projeto de Extensão. (CHICHAVA et al, 2013, p. 13)
33 E com certeza não estão descartadas as possibilidades de entrada do agronegócio
estrangeiro, especialmente com as tendências contemporâneos de "land grabs" e o
possível envolvimento com a produção de biocombustíveis. Continua a haver indícios 
o temor da União Nacional de Camponeses de Moçambique que o programa possa deixar pessoas sem terra e/ou empobrecer comunidades rurais ao torná-las dependentes de investimentos de larga escala (CHICHAVA et al, 2013, p. 15).

Tanto o ProSavana como a mineração pela Vale em Moatize podem alterar significativamente o uso e configuração do território no norte de Moçambique, em especial, as territorialidades das populações camponesas e rurais que habitam a região. A expropriação massiva de camponeses, característica de processos de "acumulação por espoliação" e das formas de modernização agrícola no século XX, é sempre um risco em projetos de desenvolvimento que privilegiam a entrada de capital na agricultura e a exportação de commodities. Tanto o ProSavana como a mina de Moatize refletem certas concepções de desenvolvimento, e inclusive parecem integrar-se numa visão mais ampla para o norte do país, como corredor de exportações - não por acaso, a Vale tem investido maciçamente no aperfeiçoamento da ferrovia que cruza o corredor de Nacala. ${ }^{34}$ Precisamos ficar atentos a

nesse sentido, como eventos e seminários promovendo investimentos do agronegócio em Moçambique, a visita de fazendeiros brasileiros ao país em 2010 e o chamado Fundo de Nacala, fundo associado à FGV para levantar capital para investimento em agronegócio no Corredor de Nacala.

34 "O próprio ProSavana está mirando uma região cuja principal importância econômica estratégica é enquanto corredor de exportação para o escoamento das 
todos esses processos em curso - nesse artigo, só foi possível evidenciar perspectivas dos grandes atores envolvidos, impulsionando esses projetos, e analisar as condições em diferentes níveis e esferas que possibilitam esses grandes empreendimentos, mas é preciso também - e assim intentamos fazer em próximas incursões no tema - atentar para as narrativas e visões das populações atingidas por esses projetos.

\section{Referências Bibliográficas}

AMIN, Samir. Underdevelopment and Dependence in Black Africa: Historical origin. In: Journal of Peace Research. Vol. 9, No. 2. Sage Publications Ltd: 1972, pp. 105-120.

AMORIM, Celso. A África tem sede do Brasil. Carta Capital. 28 mai. 2011. Disponível em: http://www.cartacapital.com.br/politica/a-africatem-sede-de-brasil. Acesso em: 24 set. 2013.

BELLUCI, Beluce. All and nothing: capital's wager in Mozambique. In: LECHINI, Gladys (edit.). Globalization and the Washington

operações de mineração brasileiras na encravada província de Tete." (CHICHAVA et al, 2013, p. 11). Tradução livre. No original: "Prosavana itself is targeting a region whose principal strategic economic importance is as an export corridor for the output of Brazilian mining operatons in landlocked Tete Province." 
Revista Vernáculo, $n^{o} 30,2^{\circ}$ sem/2012

Consensus: its influence on democracy and development in the south. Buenos Aires : CLACSO, 2008.

BERNSTEIN, Henry. Tierra rural y conflitos agrários en la África subsahariana. In : MOYO, Sam; YERO, Paris (org.). Recuperando la tierra: el resurgimento de movimientos rurales en África, Ásia y América Latina. Buenos Aires: CLACSO, 2008.

BOND, Patrick. A pilhagem na África: a economia da exploração. Rio de Janeiro : Instituto ComÁfrica, 2007.

BOND, Patrick. The Looting of Africa. In: LECHINI, Gladys (edit.). Globalization and the Washington Consensus: its influence on democracy and development in the south. Buenos Aires : CLACSO, 2008.

BOSTON CONSULTING GROUP. Allies and adversaries: 2013 BCG Global Challengers. 2013. Disponível em: https://www.bcgperspectives.com/content/articles/globalization_growth _allies_and_adversaries_2013_bcg_global_challengers/. Acesso em 25 set. 2013. 
Revista Vernáculo, $n^{o} 30,2^{\circ}$ sem/2012

CHICHAVA et al. Chinese and Brazilian Cooperation with African agriculture: the case of Mozambique. Working Paper 49, Future Agricultures, 2009. Disponível em: http://www.futureagricultures.org/research/cbaa/7817-china-and-brazil-in-africa-newpapers\#.UkvizD_3cSZ. Acesso em 16 set. 2013.

CLEMENTS \& FERNANDES. Land grabbing, agribusiness and the peasantry in Brazil and Mozambique. Paper apresentado no "International Conference on Global Land Grabbing II". October $17-19,2012$

CRÍTICA MARXISTA, edição 36. Campinas, UNICAMP, 2013.

DELGADO, Guilherme Costa. A questão agrária e o agronegócio no Brasil. In: CARTER, Miguel (org.). Combatendo a desigualdade social: o MST e a reforma agrária no Brasil. São Paulo: Editora UNESP, 2010.

FONTES, Virginia. O Brasil e o capital-imperialismo. Rio de Janeiro: EPSJV/UFRJ, 2010. 
Revista Vernáculo, $n^{o} 30,2^{\circ}$ sem/2012

GALL, Timothy; HOBBY, Jennen (edit.). Worldmark Encyclopedia of the Nations -Volume 2. Twelfth Edition. Thomson Gale, 2007.

GARCIA, Ana E. Saggioro. A internacionalização de empresas brasileiras durante o governo Lula: uma análise crítica da relação entre capital e Estado no Brasil contemporâneo. Tese (Doutorado em Relações Internacionais) - Rio de Janeiro, PUC, 2012.

GARCIA, Ana E. S. ; KATO, Karina ; FONTES, Camila. A história contada pela caça ou pelo caçador? Perspectivas sobre o Brasil em Angola e Moçambique. PACS -Rio de Janeiro, Relatório de Pesquisa, 2013.

GOÉS, Francisco; RIBEIRO, Ivo. Vale vai dar prioridade ao ferro de Carajás e ao carvão de Moçambique. Valor Econômico. 17 jul. 2013. Disponível em: http://saladeimprensa.vale.com/pt/noticias/interna.asp? $\mathrm{id}=22393$. Acesso em: 26 set. 2013.

HARVEY, David. O "novo imperialismo": acumulação por espoliação. Socialist Register, 2004. Disponível em : http://biblioteca.clacso.edu.ar/ar/libros/social/2004pt/05_harvey.pdf. Acesso em: 18 set. 2013. 
HERRERA, Silvio Baró. Neoliberalismo y crisis alimentaria em África. In: ÁLVAREZ COSTA, María Elena (org). África Subsahariana: sistema capitalista y relaciones internacionales. Buenos Aires : CLACSO, 2011.

HUMAN RIGHTS WATCH. "What is a house without food?" Mozambique's Coal Mining Boom and Resettlements. 2013. Disponível em :http://www.hrw.org/reports/2013/05/23/what-housewithout-food. Acesso em: 16 set. 2013.

LOURENÇO, Luana. Na Etiópia, Dilma defende padrão Sul-Sul de cooperação com a África. Agência Brasil. 24 mai. 2013. Disponível em:http://agenciabrasil.ebc.com.br/noticia/2013-05-24/na-etiopiadilma-defende-padrao-sul-sul-de-cooperacao-com-africa. Acesso em: 23 set. 2013.

MIDDLETON, John; MILLER, Joseph (org). New Encyclopedia of Africa - Volume 3. Gale, 2007.

MOSCA, João; SELEMANE, Tomás. El dorado Tete: os mega projetos de mineração. Centro de Integridade Pública, Maputo, 2011.

Disponível

em : 
Revista Vernáculo, $n^{o} 30,2^{\circ}$ sem/2012

http://www.cip.org.mz/cipdoc\%5C106_EL\%20DORADO\%20TETE_ Mosca\%20e\%20Selemane_CIP_2011.pdf. Acesso em: 19 set. 2013;

MOYO, Sam; YEROS, Paris. El Resurgimento de los Movimientos Rurales bajo el Neoliberalismo. In: MOYO, Sam; YEROS, Paris. Recuperando la tierra: El resurgimento de movimientos rurales en África, Ásia y América Latina. Buenos Aires: CLACSO, 2008.

NETTO, José Paulo; BRAZ, Marcelo. Economia Política: uma introdução crítica. São Paulo : Cortez, 2012.

N'KRUMAH, Kwame. Neocolonialismo: último estágio do imperialismo. Rio de Janeiro: Civilização Brasileira, 1967.

OAKLAND INSTITUTE. Understanding land investment deals in Africa: Mozambique. 2011. Disponível em : http://www.oaklandinstitute.org/understanding-land-investment-dealsafrica-mozambique. Acesso em: 19 set. 2013.

PARAGUASSU, Lisandra. Dilma quer agência de comércio para fortalecer balança. O Estado de S. Paulo. 15 jun. 2013. Disponível em: http://www.estadao.com.br/noticias/impresso,dilma-quer-agencia-de- 
comercio-para-fortalecer-balanca-,1042690,0.htm. Acesso em: 23 set. 2013.

PIERRI, Francesco Maria. How Brazil's Agrarian Dynamics Shape Development Cooperation in Africa. IDS Bulletin Volume 44, Número 4, Julho 2013. Disponível em: http://onlinelibrary.wiley.com/doi/10.1111/1759-5436.12043/abstract. Acesso em: 18 set. 2013.

PITCHER, Anne. Transforming Mozambique: The Politics of Privatization, 1975-2000. New York: Cambridge University Press, 2002.

PITCHER, Anne. Sobreviver à transição: o legado das antigas empresas coloniais em Moçambique. In: Análise Social, vol. XXXVIII (168), 2003, pp. 793-820.

RAFAEL, Adelson. Neocolonialismo brasileiro em Moçambique. O País. 24 ago. 2011. Disponível em: http://www.ihu.unisinos.br/noticias/46703-o-neocolonialismobrasileiro-em-mocambique-. Acesso em: 24 set. 2013. 
Revista Vernáculo, $n^{\circ} 30,2^{\circ}$ sem/2012

SUMICH, Janson. Construir uma nação: ideologias de modernidade da elite moçambicana. In: Análise Social, vol. XLIII (2. $\left.{ }^{\circ}\right)$, 2008, pp. 319-345.

VISENTINI, Paulo Fagundes. As revoluções africanas: Angola, Moçambique e Etiópia. São Paulo : UNESP, 2012.

ZIEGLER, Jean. Destruição em massa: geopolítica da fome. São Paulo: Cortez, 2013. 